\title{
Exploration of the Use of Educational Game Mode in Kids Teaching
}

\author{
Yulong Zuo \\ Feixian College \\ Linyi University \\ Linyi, China 273400
}

\begin{abstract}
With the development of computer and the popularization of Intelligent mobile phone, tablet computer, electronic game has been very difficult to separate from the world of the children in the kids world. As how to make rational use of educational games in the teaching, based on the analysis of the characteristics of physical and mental development of children of different age, the use of three kinds of mode of educational games in teaching young children: teaching demonstration model, cooperative learning mode, individual counseling model.
\end{abstract} model

Keywords-educational games; kids teaching; teaching

\section{INTRODUCTION}

Chinese near modern famous preschool education father Heqin Chen said "Game from education is excellent teachers for the children, let the children from the game to know the environment, from the game strong body and mind exercise, to learn about life..., The game is children's mentor." In modern society, computers, tablet PCs and smart phones have already entered the household, changing the way people live and learn, children are in such a large environment, inevitably attracted by these things, life can often see the phenomenon of children playing games with a computer or smart phone. In addition, with the improvement of our country's emphasis on preschool education and the improvement of the teaching conditions, some kindergartens are trying to use the educational games to carry on the teaching. How to use educational games in the teaching of early childhood education? Based on the analysis of the characteristics of the physical and mental development of children with different ages, this paper puts forward three kinds of educational games in early childhood education.

\section{The CHOICE OF TEACHING ModE}

The most basic principle that we must follow in the choice of teaching mode is that the education game should conform to the physical and mental development of young children in different ages. Many experts both at home and abroad have pointed out that the level of cooperative learning in early childhood has a slightly lower trend, and the development of cooperative behavior is the fastest in children aged 4 years, 4-5 years old is the level of cooperative learning. In this age, children can be very good to complete cooperative learning tasks, when disagreements or disputes, over half of the children can take the initiative to humility, there are also some children use some strategies to resolve their differences, such as "scissors burden hammer", "palm" and so on. In 4-5 years old children's cooperative learning characteristics of the most prominent is "leader", here the "head collar" refers to the role of a child in the cooperative learning group act as organizers, active members of the group of division of labor, and unable to actively participate in the activities of children to persuade. Of course, in the 2-6 years of age and the existence of cooperation behavior, but the development of children around the age of 4 is the most rapid. Japanese scholars Iwata Junichi once pointed out: "kindergarten can play together with peers, and even appeared in a small group of good relationship, which is a necessary condition for cooperative learning.

4 years old can become the key point of the development of children's cooperative behavior and cooperative learning level, the reason is mainly about 4 years old children can stand in the other side of the position to consider the problem, and can begin to speculate about the psychological state of others, such as beliefs, ideas, knowledge, etc.. Therefore, we can infer that, by using the cooperative learning model is more appropriate in the 4-5 year old infant in.

At the age of 3-4, the most important way of learning is to imitate, and they have the experience of others. A parent, a teacher, a playmate will become the children unconsciously imitated, their tone of voice, posture and common language will children imitate. For example: in the home, children if you see parents lying on the sofa watching TV, then the child will develop this bad habit, adults if they see the food in the spinach and do not like to eat, then the child will hate eating spinach. In school, if the teacher praise a child, then the whole class will be very envious the one who be prasied, and to learn from him. The teacher praised a child to do the right, then the other children will immediately be straight up to the waist. In the age of 3-4 years, the habit of children by copying and the formation of the habit will be consolidated. From this we can infer that the use of teaching model is more suitable for the 3-4 years old.

5-6 years old children's minds has been slowly began to mature, both in intellectual and emotional levels have greater progress, so for small and middle shift teaching mode under the appropriate teaching situations can reasonable use. 


\section{THREE KINDS OF TEACHING ModE AND TEACHING STRATEGIES IN THE APPLICATION OF EDUCATIONAL GAMES IN EARLY CHILDHOOD EDUCATION}

Through the long-term observation of kindergarten teaching and the interview to the kindergarten teachers, and combined with the actual situation of kindergarten software and hardware configuration, we found that there are three main types of educational games in the actual teaching of children.

\section{A. Teaching Demonstration Model}

In early childhood, children's knowledge of the reserve is less, children can only accept some of the most basic knowledge, the most basic skills. Teaching demonstration of this teaching mode is more suitable for children to learn knowledge and skills in the early stage, in this teaching mode, and is not just the use of the teacher's rigid application examples repeatedly stated, but to choose the right time to introduce educational games, the use of the game, so that children produce creative learning interest and enthusiasm. In the teaching of teaching demonstration mode, it is to combine other teaching methods to make the children learn to use the analysis, comparison, generalization, abstraction, exploration and reasoning and so on.

When using this teaching mode, teachers face all the teaching content, and the teacher is the center of the teaching, the role of education game reflects the need to provide specific image, interesting sound, vivid language and other information, can use the game to stimulate children's learning interest, at the same time, children can use the game to get a relatively real experience. Children's learning process is still under the control of the teacher, and the traditional teaching only to explain and demonstrate the difference is that children in the teaching process to operate the game, get a relatively real sense and experience, while the children with early childhood teachers to complete teaching. This classroom structure with explanation, demonstration, practice, auxiliary can reflect the teaching principle of the main body and the teacher as the leading. Although this teaching mode can not be achieved by one person in a completely personalized teaching, but still can play the interactive function of educational games. In the teaching process, the teacher can ask the child to manipulate the mouse or the keyboard to carry on the teaching game, then tells the game process. Teachers can make full use of the interactive features of the game to stimulate children's learning enthusiasm, so that teaching activities more effective.

Setting "level" is the characteristic of this kind of teaching mode, teachers are usually involved in the game with some of the knowledge points, in the game according to the level of difficulty of knowledge points set "level", so that children in the game to find the problem, and then think, to find out the problem. In the environment of the game, children can form a "cycle of feedback and interaction with the computer", child care operation is not correct, the need for children to re operation, the computer and then give feedback. The unique form of the game teaching is not achieved by other forms of teaching. It has changed the form of the traditional children's answer. In this way, children's learning process is full of novelty, children in the process of the game can be repeated trial error, and self correction, but also for the part of their own interest in the practice, and children can also be based on their own knowledge of the content of the education game, so that children in lively and interesting games to complete the teaching objectives, at the same time, children's learning ability and innovation ability is also increased. So as to make up for the form of the traditional children's answer.

\section{B. Cooperative Learning Model}

In cooperative learning mode, more than one child is required to cooperate and interact with each other in order to solve the problem so as to achieve a more profound understanding of the content of the game teaching, more firmly grasp. Many scholars have carried out a lot of research shows that the teaching of educational games can support children to take the initiative in the form of group cooperation learning and thinking. In the environment of educational games, the teachers have the opportunity to create interactive learning activities for the children. Give full play to their own characteristics of cognition together to complete tasks in the game. In the whole process, child of division of labor and cooperation, mutual help, reminded each other, learning from each other, to sum up the common, so as to get the abundant knowledge and experience. This educational game learning model requires that each child and other children to discuss each other's views, so as to share the wisdom of the collective.

Like to play with friends, is the nature of children. In actual teaching, we also found that children is not like own a personal computer controlled the operation of the game, more hope one or two playmates and he used. Teachers can give children to develop the rules of the machine, so that children can play games in discussions with friends, they will be discussed in the first issue of the small partners, this mode of teaching so that children can learn to communicate with others in the ability, but also improve the oral expression of children. In this process, the teacher should create sufficient conditions for the cooperative learning of children, and guide and supervise the learning of children in this mode.

In the actual teaching process, the teacher first explain the basic operation method of the game and the key point of the need to pay attention to the key points, and then to the children to group the operation of educational games, so that children in the operation of the exchange of free discussion. In order to ensure that all of the children can get the opportunity to operate learning, teachers should be targeted at the characteristics of different children, and to develop the rules, so as to effectively control the progress of the classroom. In the course of teaching, teachers should pay attention to the operation process of children, provide help to children in time, and the progress of the stagnation of the group targeted counseling. The teacher's views on children's representation and creative ideas can be discussed in the class. This teaching mode makes the children learn new knowledge in a relaxed and happy environment, but also 
promotes the awareness of social interaction and cooperation. The teachers can find out the information in the teaching process.

\section{Individual Counseling Model}

The model makes full use of the characteristics of educational games, and the characteristics of the two-way transmission of information, and the individual is conducted by the teachers. This kind of teaching mode embodies the teaching principle of "teaching students in accordance with their aptitude". Individual differences can be a very good solution to preschool children.

"The kindergarten education guidance program" explicitly pointed out: the early childhood education should pay attention to the individual child difference, promotes each child's rich individuality development. In the individual counseling mode, the child learning is not a collective, but a complete operation of the individual on the computer. In the prescribed time, give different levels of children fully learning conditions and opportunities, let the children to display their ability to self, which embodies the teaching principle of "teaching students in accordance with their aptitude". This model of individual counseling also allows teachers to more detailed observation of a single child, which makes the teacher's guidance more targeted. Compared with other teaching mode, this model can be used for different levels of kids, each child can refer to their own learning level and ability to learn new knowledge, so as to avoid the traditional teaching of teachers unified explanation, uniform requirements of the "one size fits all" phenomenon.

This teaching model is not restricted by the fixed pattern, which makes the children have a lot of doubt, which can promote the children's desire for new knowledge, and guide the children to seek new ways and new ideas to solve the problem.

\section{CONCLUSION}

The application of educational games in the teaching of young children is not static, we need to improve the practice teaching and research. This paper puts forward three kinds of teaching mode is the author through the field observation of the actual situation of education game teaching in kindergarten, and the first line of kindergarten teachers to carry out interviews, and then put forward the view, in order to promote the kindergarten teaching reform to provide a little help and reference. I believe that the use of educational games in early childhood education will get more and more attention and recognition, but also believe that there will be more experts and teachers in the early childhood education to the problem.

\section{REFERENCE}

[1] Wang Xiaoying, Shi Li. 3 to 6 years old children's level and characteristics of cooperative learning $[\mathrm{J}]$. Preschool education research,2008(12)

[2] Yu Kailian. Xu Xiaolong. Guo Liping. Computer and early childhood development [J]. Psychological Science, 2003 (2)
[3] Wang Shanling. Educational games a intelligence factors in children. China Education Informationization, 2007 (2) nd the cultivation of non

[4] Jinyang, Zhang Yibing. Parents of research on children and computer games [J]. Preschool education research, 2005(4)

[5] Liu Jiangping. The application of computer educational games in primary school information technology teaching [D]. Liaoning Normal University, 2012

[6] Yu Jing Shuang, Li Yubin. The influence of information technology environment on children's creative thinking. Teaching research,2009 (4)

[7] Wang Yufan. Computer information technology and early childhood education innovation education. Network technology era, 2007 (21)

[8] Xue Junyan, Xu Qin. Exploration and development of children 's Teaching Games. Contemporary Education Forum,2006 (10)

[9] Fu Xianghua,Zhou Hong. Training of Computational Thinking Ability in computer game design.Computer Education,2013 (13) 